Article

\title{
Small Drones for Community-Based Forest Monitoring: An Assessment of Their Feasibility and Potential in Tropical Areas
}

\author{
Jaime Paneque-Gálvez ${ }^{1,2, *}$, Michael K. McCall ${ }^{1}$, Brian M. Napoletano ${ }^{1}$, Serge A. Wich ${ }^{3,4}$ \\ and Lian Pin Koh ${ }^{5}$
}

1 Centro de Investigaciones en Geografía Ambiental (CIGA), Universidad Nacional Autónoma de México (UNAM), Antigua Carretera a Pátzcuaro No 8701, Col. Ex-Hacienda de San José de La Huerta, Morelia 58190, Michoacan, Mexico; E-Mails: mccall@ciga.unam.mx (M.K.M.); b.napoletano@gmail.com (B.M.N.)

2 Institut de Ciència i Tecnologia Ambientals (ICTA), Universitat Autònoma de Barcelona (UAB), Bellaterra 08193, Barcelona, Spain

3 School of Natural Sciences \& Psychology, Liverpool John Moores University, James Parsons Building, Byrom Street, Liverpool L3 3AF, UK; E-Mail: s.a.wich@ljmu.ac.uk Institute for Biodiversity and Ecosystem Dynamics, University of Amsterdam, Science Park 904, Amsterdam 1098 XH, The Netherlands

5 Environment Institute and School of Earth and Environmental Sciences, University of Adelaide, Adelaide, SA 5005, Australia; E-Mail: lianpinkoh@gmail.com

* Author to whom correspondence should be addressed; E-Mail: jpanequegalvez@gmail.com; Tel.: +52-443-222-777; Fax: +52-443-322-38-80.

Received: 11 February 2014; in revised form: 6 June 2014 / Accepted: 16 June 2014 / Published: 24 June 2014

\begin{abstract}
Data gathered through community-based forest monitoring (CBFM) programs may be as accurate as those gathered by professional scientists, but acquired at a much lower cost and capable of providing more detailed data about the occurrence, extent and drivers of forest loss, degradation and regrowth at the community scale. In addition, CBFM enables greater survey repeatability. Therefore, CBFM should be a fundamental component of national forest monitoring systems and programs to measure, report and verify (MRV) REDD+ activities. To contribute to the development of more effective approaches to CBFM, in this paper we assess: (1) the feasibility of using small, low-cost drones (i.e., remotely piloted aerial vehicles) in CBFM programs; (2) their potential advantages and disadvantages for communities, partner organizations and forest data end-users; and (3) to what extent their utilization, coupled with ground surveys and local ecological knowledge,
\end{abstract}


would improve tropical forest monitoring. To do so, we reviewed the existing literature regarding environmental applications of drones, including forest monitoring, and drew on our own firsthand experience flying small drones to map and monitor tropical forests and training people to operate them. We believe that the utilization of small drones can enhance CBFM and that this approach is feasible in many locations throughout the tropics if some degree of external assistance and funding is provided to communities. We suggest that the use of small drones can help tropical communities to better manage and conserve their forests whilst benefiting partner organizations, governments and forest data end-users, particularly those engaged in forestry, biodiversity conservation and climate change mitigation projects such as REDD+.

Keywords: unmanned aircraft systems; unmanned aerial vehicle; remote sensing; tropical forests; community-based forest management; REDD+; MRV; national forest monitoring and safeguard information systems; deforestation and degradation; conservation

\section{Introduction}

Tropical forests play a critical role in the global carbon cycle [1] and harbor around two-thirds of all known species [2]. Large tracts of tropical forests have long been inhabited by humans, thus leading to a significant overlap between linguistic, cultural and biological diversities [3]. Presently, tropical forests are also home to a significant proportion of the world's poor [4], and therefore synergies between poverty alleviation and forest conservation strategies are essential for successful conservation [5]. In tropical regions, it is claimed that community-based forest management has the potential to both alleviate poverty [6] and be more effective for forest conservation than protected areas $[7,8]$. Though such claims are not clearly supported by quantitative evidence [9], community-based forestry continues to be central to many development and conservation projects worldwide. In such efforts, sound community-based forest management strategies have to be developed in combination with community-based forest monitoring (CBFM) [10] strategies so that a range of assessments can be made over time and management can be adaptive.

Likewise, CBFM will be essential to the successful implementation of the Reduced Emissions from Deforestation and Forest Degradation (REDD+) program [11] across tropical communities because CBFM has significant advantages over governments and other organizations working in community forests [12-14], and because local participation is essential to improving forest governance [15-17] and constitutes a fundamental safeguard under REDD $+[18,19]$. Thus, for instance, forest data gathered by trained community members have been shown to be as accurate as those gathered by professional scientists, but at a much cheaper cost, and can provide greater survey repeatability and more detailed data about the occurrence, extent and drivers of forest loss, degradation and regrowth at the community scale [12,13,20-24]. CBFM can also supplement [25] existing national forest inventories in tropical countries [20,26] and should therefore be a fundamental component in national forest monitoring systems and in systems to measure, report and verify (MRV) REDD+ activities, which to date are inadequate in most REDD+ project sites [27]. Furthermore, CBFM could facilitate 
the transition from centralized forest monitoring approaches to more transparent, independent and widespread models, which should deliver substantial benefits [28]. In addition, CBFM can help communities deter people (whether locals or abutters) from carrying out illegal activities in their territories, hence contributing to improved forest governance [29]. CBFM may also lead to the social and institutional strengthening of communities, empowered by the use of technologies and greater knowledge and awareness of policies, which in turn may enhance their ability to negotiate claims in REDD+ and to help achieve equitable, efficient and effective REDD+ outcomes [12,20,22,23]. For all these reasons, CBFM can improve forest monitoring in tropical countries, with potential co-benefits for biodiversity conservation, climate change mitigation and livelihood support [12,30].

CBFM is usually carried out through conventional ground surveys to gather forest data inventories by measuring variables in permanent plots such as diameter at breast height (dbh), tree height, percentage of canopy cover, number of trees and tree species. Such surveys cover a very small area and are usually costly, time-consuming, tedious, and plagued with logistical difficulties in the tropics (e.g., safety, access to remote sampling sites). In order to develop more effective approaches to CBFM, in this paper we assess: (1) the feasibility of using small, low-cost drones (remotely controlled aerial vehicles) in CBFM programs; (2) their key advantages and disadvantages for communities, partner organizations and forest data end-users; and (3) to what extent their utilization, coupled with ground surveys and local ecological knowledge, would improve tropical forest monitoring, particularly in light of the needs of REDD+ MRV systems, as compared to using only ground surveys or ground surveys coupled with other remote sensing approaches. Our assessments are timely and necessary because although drones are being increasingly used for a range of environmental monitoring tasks with reasonable success, we do not know of any programs now being developed to use small drones for CBFM. To our knowledge, this is the first paper that evaluates the prospects, challenges and opportunities of using small drones for CBFM in tropical areas as a way to improve forest monitoring, which is central to effective REDD+ implementation. The subject is very topical and relevant as reducing and preventing tropical deforestation and forest degradation is a vital global climate mitigation strategy [31,32], and key to sustain global biodiversity [2].

We reviewed both academic and non-academic literature dealing with the use of small drones [33] for environmental applications, including forestry. We first provide a brief overview of such uses, including the types of drones that could be employed specifically for CBFM. We then outline and briefly discuss the key advantages and disadvantages that we expect from the use of small drones for CBFM, according to how we envisage the whole process in the short-term, which includes some external training, assistance and funding from organizations working alongside communities (e.g., in REDD+ projects) so that drones can be operated by communities; we evaluate the pros and cons from the standpoint of communities, partner organizations and forest data end-users. In addition, we provide a brief assessment regarding the improvements we expect in forest monitoring by means of implementing this drone-assisted CBFM approach, particularly in relation to REDD+ MRV systems needs, and discuss the main prospects, challenges and opportunities for implementing this approach at present and in the near future. We ground our assessments on the authors' own experiences in community forest management and monitoring in several tropical contexts as well as our expertise in the remote sensing of forests, a literature review of drone applications in environmental monitoring, 
and firsthand experience flying small drones for mapping and monitoring tropical forests and training people to operate them.

\section{The Use of Small Drones for Environmental Mapping and Monitoring}

As with technologies such as GPS, small drones were initially developed for military use, but are increasingly being deployed in civilian applications [34], including mapping, monitoring and managing habitats and natural resources. Although small drones are not used widely in environmental applications yet, their use is likely to increase rapidly as their prices decrease and the technology becomes easier to use [35,36].

The earliest scientific publications of environmental data gathered with small drones were studies carried out by Tomlins, Lee and Manore using a hobby-grade model aircraft, and later a custom-designed small drone [37-39]. In his pioneer research, Tomlins identified as many as 46 environmental applications in which small drones could be useful [37]; yet this technology remains unexplored for most such applications [40]. Although some initial attempts were made to employ small drones in environmental research in the 1990s and early 2000s (e.g., [41,42]), researchers have only begun seriously investigating the use of drones over the last seven to eight years. Recent papers discuss the potential benefits of small drones for specific environmental applications (e.g., [43-46]), including a recent special issue on the topic published in 2011 in GIScience and Remote Sensing (see [47]).

Although the development of environmental remote sensing technologies and methods has been closely related to the study of forests (e.g., [48-52]), the bulk of the academic literature published about the development and use of small drones for environmental applications is not concerned with forests. Instead, the focus is on the use of small drones in precision agriculture (e.g., [46,53,54]) and vegetation monitoring in rangelands (e.g., [44,55-59]). Other environmental research applications found in the literature include biodiversity monitoring [60-64], habitat monitoring [65-67], and soil properties $[68,69]$. Another application that can assist in environmental monitoring is the generation of high spatial resolution digital surface/elevation models from drone imagery [70,71].

Most drone research on forests has focused on mapping and monitoring fires [72-75], but some studies have aimed to monitor forest stands with small drones [60,76-84]. A pioneer study by Horcher and Visser [85] emphasized the potential use of small drones for forestry applications, and Koh and Wich recently published a paper that outlined some tasks geared toward tropical forest conservation that can be accomplished by "conservation drones" [86]. Our review of non-academic literature [87] suggests that small drones are increasingly being used by timber companies and government forestry agencies for applications such as tree crown/gap mapping, forest stand mapping, volume estimation, wind blow assessment, pest monitoring, and harvest planning. Additionally, conservation NGOs and staff of protected areas worldwide are becoming interested in using small drones for conservation-related tasks (e.g., surveillance of wildlife, monitoring of land-use change and illegal activities within reserves such as poaching and illegal game hunting) [88].

\section{Small Drones Suitable for Community-Based Forest Monitoring}

Existing drone types can be classified according to a range of criteria, including size and payload [89], control systems, flight range, altitude and endurance. A very simple classification based 
on flying altitude is provided by Everaerts [90], another based on flying altitude and range can be found in [40], and a more comprehensive classification following military-standard criteria (though focused on environmental applications) is provided by Watts et al. [45]. Most environmental applications use small drones that have light payloads, can cover relatively short distances, and are only able to fly missions over short periods of time and at low altitudes [91]. Within the category of small drones, we distinguish three main types according to their design and flight mode: (1) various balloons, blimps, kites and paragliders; (2) rotary-wing aircraft; and (3) fixed-wing aircraft (Figure 1 shows rotary- and fixed-wing aircraft that we have used).

Figure 1. Examples of rotary-wing $(\mathbf{a}, \mathbf{b})$ and fixed-wing drones $(\mathbf{c}-\mathbf{f})$ used by ConservationDrones.

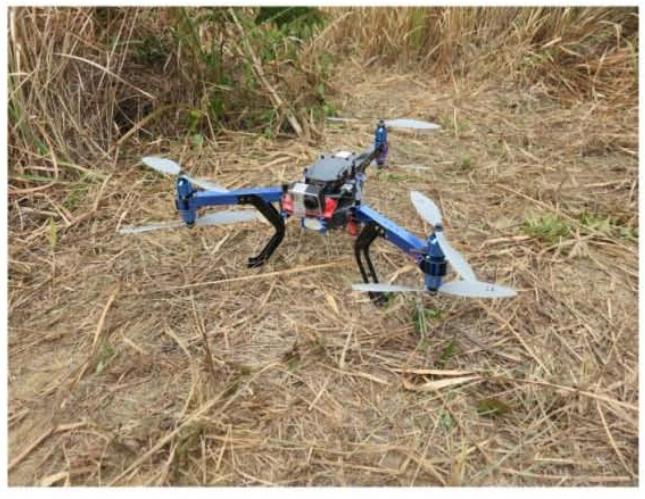

(a)

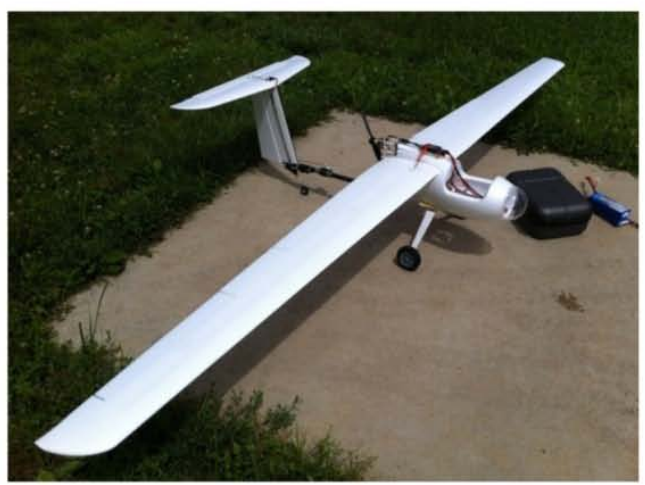

(c)

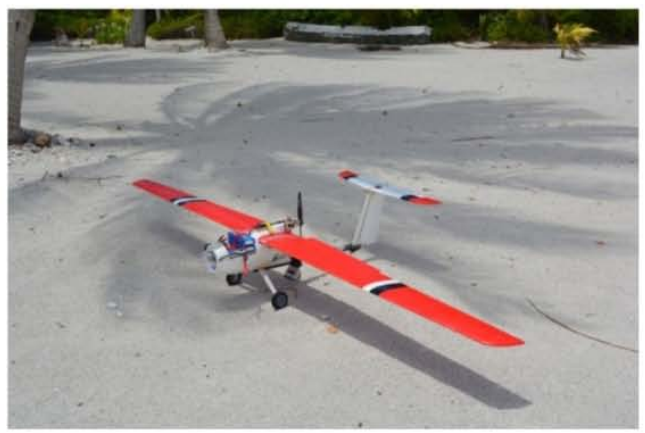

(e)

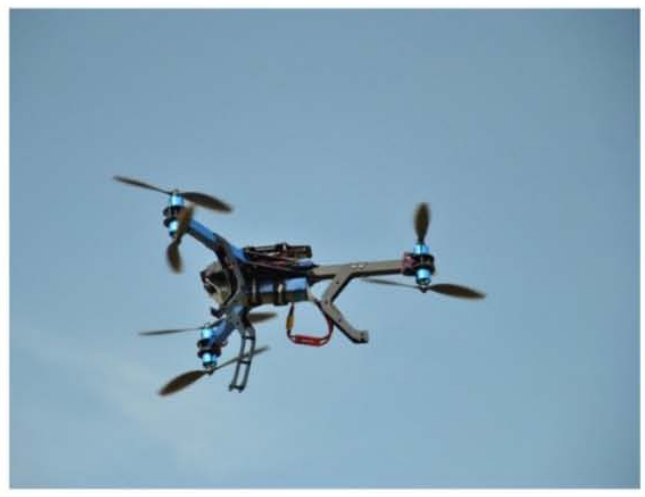

(b)

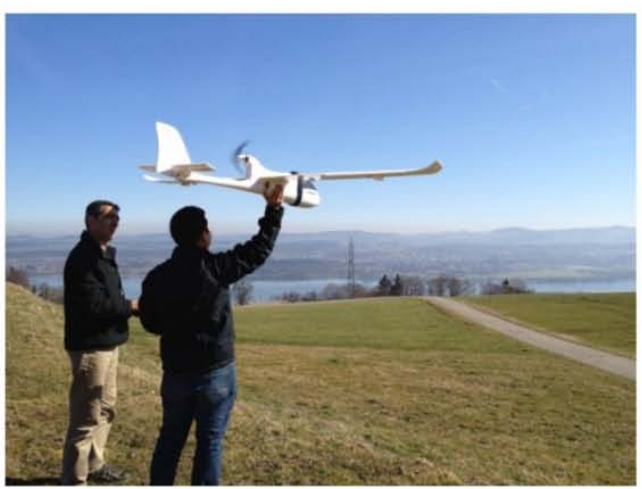

(d)

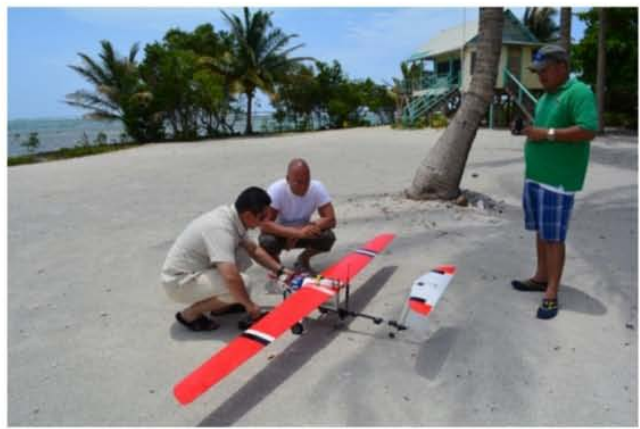

(f) 
For the purposes of CBFM, balloons, blimps, kites and paragliders are not suitable because it would be very difficult to cover large areas with these systems and therefore they are best utilized for very local monitoring needs (e.g., permanent monitoring at key areas for fire/smoke detection). Rotary-wing aircraft such as helicopters and multicopters (e.g., quadracopters, octocopters) may not be well suited for CBFM in large community forests because these drones can only cover short distances [92] for short durations (typically up to 30 or even $40 \mathrm{~min}$ ) owing to their high power demand relative to their limited battery size. However, they may be more useful than fixed-wing drones in instances where canopy gaps are large enough for vertical ascent [93] and descent, but no landing strip is available. In contrast, fixed-wing aircraft have gliding capabilities that enables greater flight endurance than rotary-wing aircraft, which allows them to operate over the longer distances (up to $15-20 \mathrm{~km}$ ) that CBFM frequently requires in tropical forests. In addition, many fixed-wing drones can be built from hobby-class model aircraft, which may significantly reduce their cost and provide greater payload flexibility $[40,86]$. Both rotary- and fixed-wing drones can either be flown fully manually by a ground operator with the assistance of live telemetry systems or be easily pre-programmed to fly fully autonomously when an autopilot system is fitted into the drone's body (though partial ground control is recommended for safer landing and take-off).

Given these advantages, we recommend the use of small fixed-wing aircraft for CBFM and our assessment here is primarily concerned with such drones [94], although many of the advantages and disadvantages we discuss in this paper apply to rotary-wing aircraft as well. We prioritize full or semi-automation of drone flights because a higher degree of autonomy implies that a community could begin monitoring with less training than that required by fully manual operation. However, some degree of manual operation will most likely be necessary in certain situations (e.g., to interrupt a mission if required). In such cases, a telemetry system would allow for active manipulation of the flight from a laptop, tablet, or special goggles, and such manipulation is relatively straightforward after training. If manual operation of a drone is necessary, the telemetry system can stabilize the flight altitude, thus avoiding significant geometric problems in the imagery acquired.

\section{Key Advantages of a Drone-Assisted Community-Based Forest Monitoring Approach}

In this section we outline and briefly discuss key advantages we have identified for communities, partner organizations and forest data end-users [95] to using small drones for CBFM to complement community ground surveys. In the subsequent section we examine the main disadvantages. In addition, we provide a qualitative assessment of the relative importance of every advantage to communities, partner organizations, and forest data users.

The lists of advantages and disadvantages in this section and the next refer to the benefits and limitations we foresee for communities, partner organizations and forest data end-users wishing to implement a drone-assisted CBFM approach. This serves as a first assessment of the feasibility and desirability of this approach to CBFM in comparison with what could be achieved by ground surveys alone, or by ground surveys coupled with other remote sensing options (i.e., satellite or piloted aircraft imagery). Our lists are based on how we envision the entire CBFM process to proceed over the next few years. Specifically, we suggest that community members would be able to autonomously plan and acquire drone imagery to monitor their forests after receiving adequate training from a partner 
organization, and would be able to mosaic and visually inspect the imagery to detect forest change and other information important to the community. We would, however, expect partner organizations to undertake more complex geospatial analyses. This approach would also entail external assistance for drone maintenance and repair [96], as well as continued funding to secure drone operation by community members.

The key advantages identified are presented and discussed according to technical issues (e.g., sensing capabilities, drone operation and maintenance skills, image analysis, monitoring capabilities, potential to enhance and ease CBFM), social issues (implications for people in communities), and environmental issues (implications for the local environment). See Table 1a for a synopsis of all the advantages and their relative importance to communities, organizations and end-users. Although we are addressing CBFM in a broad sense, we discuss some specific issues with special reference to the needs of REDD+ MRV programs because we expect this drone-assisted CBFM approach to be particularly attractive to national and international organizations involved in REDD + who will have the capacity to provide the necessary training, assistance and funding that communities would require.

- Extremely high spatial resolution. The operational flying altitude of small drones, usually in the range of 50-300 m, permits the acquisition of extremely high spatial-resolution imagery, with pixels on the order of a few centimeters (rather than a few meters). This feature greatly enhances the visual analysis of imagery and thus can significantly improve CBFM. For instance, at this spatial resolution, specific trees and canopy gaps can be identified and easily monitored (see Figure 2). Furthermore, forest loss, degradation and regrowth processes could be accurately detected and monitored at this level of detail [97] by trained community members. Such data would not just be relevant for partner organizations and end-users, but also for communities themselves. For the former, the hyperspatial resolution of drone imagery would enable monitoring of many forest traits that currently are unachievable (at least accurately) through other remote sensing datasets. These include the identification of individual tree species by coupling imagery with botanical expertise, the detection of invasive plant species and pests, the estimation of aboveground biomass (where allometric equations exist for specific tree species), and the identification of different stages of forest regeneration or degradation, all of which are fundamental to assessing forest health condition, carbon storage and biodiversity levels, and hence to conservation and climate change mitigation policies. Although the retrieval of such information can be potentially accomplished by ground surveys alone, the use of small drones would also allow detailed mapping over much larger areas than ground surveys, and imagery at this spatial resolution should be much more meaningful to communities than ground survey data at the plot level.

- Potential for high temporal resolution. The comparatively lower cost of operation and maintenance of small drones allows users to acquire imagery far more frequently than with conventional remote sensing technologies such as satellite and piloted aircraft imagery. This means that community drone users would have the potential to update their imagery and compile high-resolution time-series imagery that would allow thorough assessments of local forest condition at much shorter intervals. Survey frequency could be decided according to organizations' and end-users' needs (so long as there is agreement with communities beforehand). This key 
feature would enable year-round monitoring of tropical forests, which is critical to improving tropical deforestation and degradation monitoring [98] because seasonal differences in canopy structure may be significant and therefore difficult to detect with single-date imagery. Tropical dry forests, for instance, exhibit a seasonal phenology associated with a long and severe dry season [99] and, therefore, require frequent observations to capture such phenological variations.

Table 1. Qualitative assessment of the main advantages (a) and disadvantages (b) expected in the adoption of a drone-assisted community-based forest monitoring program, from the perspective of communities, partner organizations, and end-users.

\begin{tabular}{lrrr}
\hline (a) Advantages & c & o & u \\
\hline Extremely high spatial resolution & 1 & 1 & 1 \\
Potential for high temporal resolution & $1-2$ & 1 & 1 \\
Insensitivity to cloud cover & $2-3$ & 1 & 1 \\
Potential for three-dimensional drone image generation & 3 & $1-2$ & 1 \\
Potential to ease CBFM and make it more attractive to communities & 1 & $1-2$ & 3 \\
Shallow learning curve of drone users & 1 & 1 & 3 \\
Relatively low price of drone imagery & $2-3$ & 1 & 1 \\
High cost-effectiveness within the context of CBFM & $2-3$ & 1 & $2-3$ \\
Data acquisition decentralization & 1 & $1-2$ & $2-3$ \\
Enhanced monitoring of illegal activities & 1 & $1-2$ & $2-3$ \\
Access to otherwise inaccessible areas & 1 & $2-3$ & 3 \\
Potential environmental benefits & $1-2$ & $2-3$ & $2-3$ \\
Potential social and institutional strengthening of communities & 1 & $2-3$ & $2-3$ \\
Control of data acquisition and ownership would lie in community members' hands & 1 & $1-2$ & 3 \\
\hline (b) Disadvantages & $\mathbf{c}$ & $\mathbf{0}$ & $\mathbf{u}$ \\
\hline Small payload & 3 & $2-3$ & $1-2$ \\
Low spectral resolution & 3 & $2-3$ & 1 \\
Poor geometric and radiometric performance & 3 & $2-3$ & 1 \\
Low software automation & 3 & $2-3$ & 1 \\
Sensitivity to atmospheric conditions & $2-3$ & $1-2$ & $1-2$ \\
Short flight endurance & $1-2$ & 1 & 1 \\
Possibility of collisions & 1 & 1 & 3 \\
Potential problems for repairs and maintenance & 1 & 1 & 3 \\
Dependence on external assistance and funding & 1 & 1 & $2-3$ \\
Ambiguous or cumbersome regulatory environments for flying small drones & 1 & 1 & 1 \\
Safety \& security issues & 1 & 1 & $1-2$ \\
Debatable relevance for community conservation and socio-economic development & $1-3$ & 1 & 3 \\
Potential social impacts & 1 & 1 & $2-3$ \\
Ethical issues & 1 & 1 & $1-2$ \\
\hline
\end{tabular}

Notation: $\mathrm{c}=$ community, $\mathrm{o}=$ partner organization, $\mathrm{u}=$ end-user. Values refer to importance scores as follows: 1 = high, 2 = medium, 3 = low. More than one value (i.e., 1-2, 2-3, or 1-3) is also allowed and indicates that the importance of a particular advantage/disadvantage for c/o/u will be case-specific. For instance, the potential for high temporal resolution will be very important (value $=1$ ) for communities with territorial problems because high re-survey frequency would allow for improved territorial surveillance, but not so important for other communities (value $=2$ ). 
Figure 2. Examples of imagery gathered by small drones that show the extremely high spatial resolution that can be achieved. (a) Danau Girang (Sabah, Malaysia); (b) Chitwan National Park (Nepal); (c) Palm oil plantation by river (Indonesia); (d) Recently logged forest (Indonesia). Imagery provided by ConservationDrones.

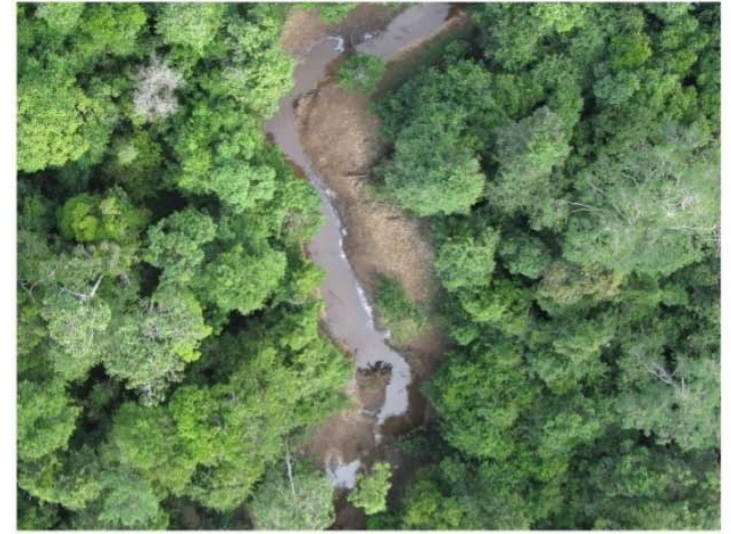

(a)

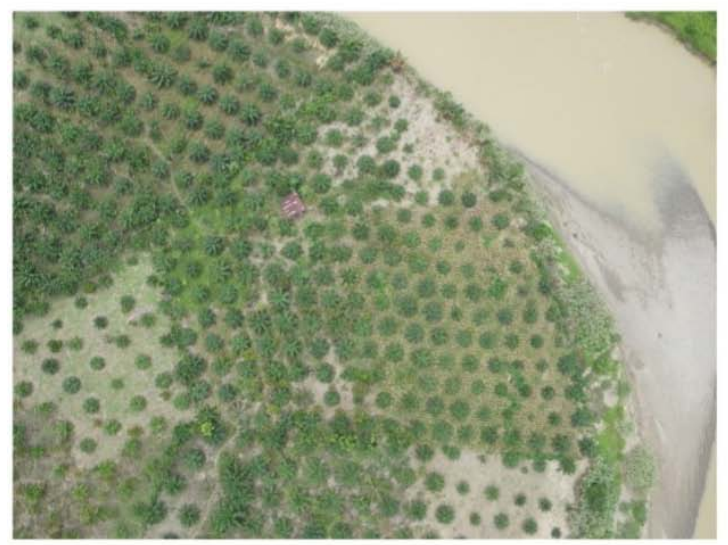

(c)

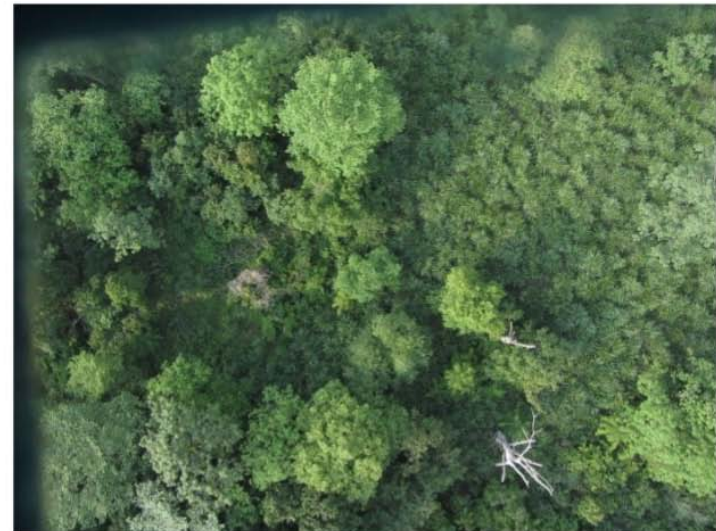

(b)

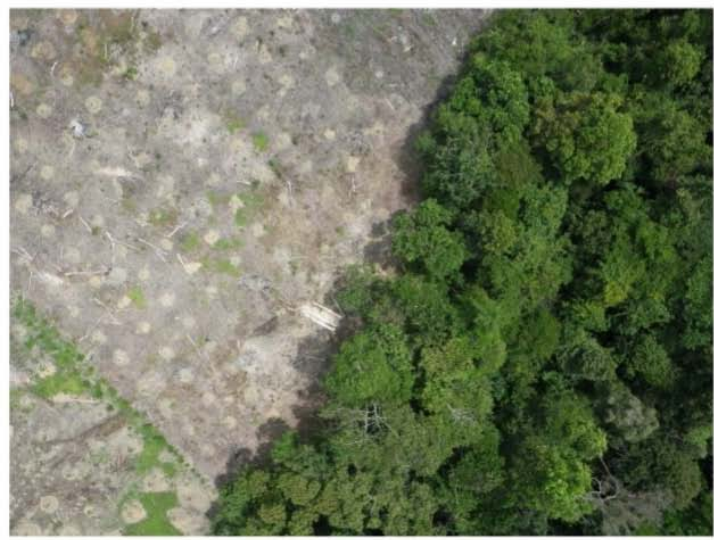

(d)

- Insensitivity to cloud cover. Small drones typically fly below cloud level (e.g., 50-100 m), which gives them a significant advantage over conventional remote sensing platforms, particularly in habitats with frequent dense cloud cover such as lowland rainforests and montane tropical cloud forests. Data provided by CBFM with small drones could greatly improve digital imagery of these cloud-covered regions, which would also benefit forest agencies and data end-users.

- Potential for three-dimensional drone image generation. Small drones are increasingly used for digital surface/elevation model generation [70,71]. The potential to apply 3-D imagery would seriously improve some tasks required to enhance forest monitoring strategies (e.g., the detection and quantification of forest degradation and regrowth stages). Also, the possibility of producing very accurate 3-D forest models with small drones would assist in the retrieval of forest structural parameters such as height, basal area, and tree density. In turn, this would improve the estimation of above-ground biomass, something urgently needed for improved carbon storage assessments in tropical forests [100]. Though the generation of 3-D products 
would be undertaken by data end-users and be particularly useful to them, 3-D maps might also represent a meaningful way for communities to better understand different features of their territories, including their forest resources.

- Potential to facilitate CBFM and make it more attractive to communities. Owing to the hyperspatial resolution of drone imagery and the potential for high survey frequency, a drone-assisted CBFM approach has the potential to ease CBFM in comparison with a conventional approach. For instance, forest strata within communities could be far more accurately delineated into homogenous units using small drones, which in turn could reduce the number of permanent ground plots needed per strata, and the number of attributes to be measured on the ground (e.g., canopy cover). In addition, the ability to survey the entire community territory with a few flights suggests that small drones could lead to significant time savings in monitoring and community data analysis, particularly in the case of medium- and large-sized community territories (i.e., hundreds to several thousand hectares). Moreover, the acquisition of high spatial and temporal resolution drone imagery would be far more meaningful to communities than the mere retrieval of plot-level forest data and, consequently, the utilization of drones would make CBFM more attractive to forest communities.

- Fast learning curve of drone users. Small drones can be programmed to operate either fully or semi-autonomously by users with relatively little training and geomatic knowledge. The commercial drone market is increasingly targeting people with little experience flying small drones and the smallest ones are particularly easy to fly by individuals with little training, so they would be appropriate for forest community members after receiving specific hands-on training from partner organizations. For instance, besides pre-programming flight paths and manual drone operation (flying, landing and take-off), setting up necessary components (e.g. GPS, photo/video camera) and downloading the acquired imagery onto a computer are all relatively straightforward tasks. Also, the geotagged drone images acquired could be mosaicked or overlaid onto Google Earth by community members after training so that they could carry out visual analyses of their forests [101]. Overall, training is relatively straightforward and varies from 1-5 days (in cases where trainees are familiar with computers) to 14 days (in cases where trainees have no prior experience with computers). In practice, the skills, innate ability and motivation for these technical activities are more likely to be found amongst younger community members.

- Relatively low price of drone imagery. The outlay required for purchasing, operating and maintaining a small drone is rather low when compared with the cost of commissioning piloted aircraft missions or acquiring imagery from any of the high spatial-resolution satellites available (e.g., IKONOS, QuickBird, RapidEye) on a regular basis. Cheap drones already exist for uses such as those discussed here. Koh and Wich [86], for instance, used a self-made conservation drone for tropical forest monitoring at an estimated cost of US\$2,000, and are currently developing and testing cheaper models [102]. Small drone prices are expected to diminish swiftly, whilst simultaneously technical capabilities are improving (as is the case for most technology developments). Off-the-shelf solutions are available for anywhere up from US\$3,000. Furthermore, there is a potential future in 3-D printed drones of sufficient specifications and capacity as the costs rapidly decrease; these are still in research and 
development status but progressing fast [103-105]. Organizations would not need to purchase expensive software to allow communities to program the missions and download the data, nor to process the imagery, as open-source solutions are already available and could be used along with their in-house software capabilities. Alternatively, organizations could outsource at a relatively low cost the pre- and post-processing of drone imagery gathered by communities. Many of the companies that manufacture and sell small drones also offer low-fee services that include imagery uploading, processing, ortho-mosaicking, and other analyses that may be needed (e.g., digital elevation models).

- High cost-effectiveness within the context of CBFM. The ability to survey all the community territory with a few flights would make the coupling of small drones with ground surveys more cost-effective than ground surveys alone. This is particularly pertinent if payments for monitoring are involved, because significantly less time would need to be devoted to surveys (at least for medium- and large-sized community territories, i.e., hundreds to several thousand hectares), and the approach remains cost effective when the costs of training community members in drone operation are factored in. If many communities in a region wish to employ small drones, however, it may be more effective to have a single small drone owned and operated by a consortium of communities (if they exist), a regional-scale NGO that participates with the communities, or, in some circumstances, a local authority that has sound relationships with the communities involved.

- Data acquisition decentralization. This has substantial advantages not just for communities but also for partner organizations and forest data end-users, including government agencies [28]. For instance, gathering forest data through a drone-assisted CBFM approach would permit the creation or enhancement of national forest inventories in tropical countries, thus potentially improving the management of community forest resources and their participation in REDD+ projects [26]. We propose that prior to setting up a CBFM system supported by small drones, communities would agree with partner organizations on the frequency of image acquisition, spatial resolution and delivery format, and the accompanying information which communities would pass on to organizations (e.g., other data from complementary ground surveys, qualitative data on forest change drivers).

- Enhanced monitoring of illegal activities. Illegal timber extraction could be monitored with these systems, not only by monitoring forest cover change with time-series photography, but also by locating extraction trails and regular monitoring of the boundaries in real-time with videography [85]. Fire and illegal land-use change that alter forest cover (e.g., cropping, pasture expansion) could also be monitored timely, as could illegal exploitation of forest resources and wildlife poaching [86]. The enhanced ability of small drones to monitor illegal activities could be of great significance for communities whose land or other resources are being stolen by abutters, as is often the case in many tropical forests [106].

- Access to inaccessible or remote areas. Areas difficult to access within a community territory (e.g., steep slopes, rocky terrain, swamps, mangroves) could be surveyed with small drones [85]. In addition, remote territorial areas could be more easily reached by small drones. This would be particularly useful in forest communities with low population densities and large territories, which are common in many tropical countries. 
- Potential environmental benefits. The use of small drones can substitute for the need for community members to open forest trails to reach and survey dense forest patches, thus reducing forest degradation and the risk of affecting rare or sensitive species. Additionally, the relatively quiet operation of small drones does not seem likely to disturb or distress wildlife and people [85].

- Potential social and institutional strengthening of communities. Similar to other mapping technologies (e.g., GPS, participatory GIS), the use of drone technology has the potential to empower forest communities. Such empowerment might lead to their social and institutional strengthening and communities might then be in a much better position, for instance, to negotiate payments under REDD+ or other PES programs (e.g., [12,22,23]). Thus, capacity-building in this arena may help forest communities access new financial assets.

- Control of data acquisition and ownership would lie in community members' hands. Based upon an appropriate agreement with partner organizations, community members could acquire imagery as often as desired [107] in order to gather relevant information for themselves (e.g., for monitoring illegal activity in specific conflict zones) and that required by outside organizations (e.g., related to REDD+). Thus, communities would not need to adapt to a strict monitoring operations calendar independently set up by government agencies or companies in charge of satellites or piloted aircraft. Community drone users should have no legal restrictions regarding data acquisition as long as they do not violate flying regulations specific to small drones, whether safety, nuisance, or privacy. Moreover, data should be owned by the community so that it can become a relevant actor in any negotiation regarding their forests, particularly in connection with REDD+ projects.

\section{Key Disadvantages of a Drone-Assisted Community-Based Forest Monitoring Approach}

In this section we discuss the key disadvantages of using small drones in CBFM (see Table $1 \mathrm{~b}$ for a list of all the disadvantages and their relative importance for communities, organizations and end-users). As before, we discuss disadvantages in a broad sense while considering the specific needs of REDD+ MRV systems.

- Small payload. Small drones are greatly constrained by the amount of equipment they can carry onboard owing to their small size and low weight. This limits the quality of the imaging sensors that can be fitted into a small drone, which together with the high price of professional small imaging sensors, hampers the acquisition of certain types of data and, therefore, of certain types of analyses that organizations and end-users might want to undertake.

- Low spectral resolution. Although small drones can be outfitted with a variety of sensors (e.g., multispectral, hyperspectral, lidar, radar) tailored to the specific needs of users, the high costs of such high spectral-resolution sensors makes their utilization unlikely in the case of CBFM, particularly if many communities wish to participate in the CBFM approach presented here for programs such as REDD+. However, the conventional RGB digital cameras frequently used in small drones might not suffice for certain tasks associated with scientific forest monitoring (e.g., leaf physiological properties), which need greater spectral resolution. 
- Poor geometric and radiometric performance. First, because small drones are so much lighter than spaceborne and airborne sensing platforms, they are far more susceptible to pitch, roll and yaw distortions, which in turn affect the possibility of accurately georeferencing the imagery acquired. This problem is further aggravated by typically insufficient state-data recorded by low-cost small drones. Therefore, geometric distortions may be difficult to resolve even for remote sensing experts. In addition, accurate ground control points may be needed for image registration and ortho-rectification, which might be difficult for community members to gather due to the absence of evident landmarks over forested regions. Second, because cheap digital cameras are frequently used instead of professional imaging sensors, poor radiometry in image mosaics may lead to inaccuracies in the products derived. These geometric and radiometric problems may only be a problem for end-users when very accurate products are needed, however, and improvements in small drone technology are expected to overcome these issues within the next few years.

- Low software automation. Most common image pre-processing and processing tasks still require improvements in automation so that complex analyses can be done faster by organizations and end-users. This includes stitching imagery over densely forested areas and geometric and radiometric corrections if a great level of accuracy is needed, particularly in the case of time-series analyses. But again this issue is being rapidly improved by remote sensing software developers.

- Sensitivity to atmospheric conditions. Although small drones can usually fly sufficiently low so as not to be affected by cloud cover, other atmospheric conditions such as fog, heavy rain, and strong and variable winds can hinder their operation. For best imaging accuracies, wind speed should be as low as possible and, depending upon the specific drone model, typically they should not be higher than $15-25 \mathrm{~km} / \mathrm{h}$.

- Short flight endurance. This is potentially a very significant constraint because the low weight capacity severely restricts the size of the batteries a drone can carry. Nonetheless, this should not be a major constraint for CBFM unless a community's territory is very large. Flight times of around 50-60 min are currently feasible and can image up to 500 ha for a flight at $250 \mathrm{~m}$ altitude, which results in an extremely high spatial resolution of less than $10 \mathrm{~cm}$ per pixel side [108]. Several such missions could potentially be flown during one day from different locations within the community and thus map a relatively large area.

- Possibility of collisions. Small drones are not usually equipped with warning or evasion systems, and collisions can occur if flight input coordinates are entered incorrectly or if something enters their flight path [85]. There are dangers of collisions with power lines, cell phone masts, etc., especially with inexperienced operators. Due to their airframe fragility, collisions pose a significant risk to small drones and warrant the need for training and acquiring expertise on flight path setting and manual maneuvering when needed. Yet, as drone operators would be community members who know the area well, this is not expected to be a major issue after adequate training. The availability of reliable digital terrain models might help better set up the flight altitude in mountainous areas, thus alleviating the possibility of collisions.

- Potential problems for repairs and maintenance. Drone repair is difficult for non-experts. This may pose a significant problem if crashes occur, the drone or any component breaks down, or 
something is lost or stolen. Hiring a mechanic or sending the drone for repair to the partner organization may significantly increase the operating cost and loss of flying time. Though such problems are rapidly decreasing due to technological improvements, without securing funds and trained personnel to perform repairs and maintenance as necessary, we would expect the utilization of drones in CBFM to be severely hampered in the short-term. A well-prepared operational plan for how to deal with these contingencies is essential.

- Dependence on external assistance and funding. Along with the need for assistance whenever a community-operated drone breaks down or needs maintenance, communities would be very dependent on initial training and continued funding from partner organizations or government agencies. However, determining the amount of external assistance needed for community training and how much external funding is necessary requires further investigation. Nevertheless, we expect this disadvantage to diminish rapidly as technology is fast improving in terms of cost, quality and ease of use.

- Ambiguous or cumbersome regulations for flying small drones. The laws of many countries regarding the use of small drones are ambiguous. For example, in the USA, strict regulations and a cumbersome permit process impede their use, particularly in the case of non-commercial models. Strict regulations are repeatedly highlighted as a major impediment to the widespread adoption of small drones in research and civil applications [40,45,109]. In most tropical countries, however, clear regulations do not exist yet, and we do not expect very strict regulations for environmental applications such as CBFM. Actually, flying permits may not be needed for CBFM in communities with secure land tenure arrangements as long as flights are kept at low altitudes within community property.

- Safety and security issues. The operation of small drones in dangerous territories, such as community forests where illegal logging and farming, poaching, illegal drug production, land encroachment, or military activities might be taking place, may pose significant threats to the security of the drone operators, other community members, and even the partner organizations' personnel involved in the CBFM program. Although this is not a specific problem of drones, illegal actors might feel more intimidated by small drones than by people on the ground if they know of their surveillance capabilities (e.g., video recording).

- Debatable relevance for community conservation and socio-economic development. Communities must have a clear interest and commitment toward monitoring their forest resources in a "scientific" manner, particularly if they wish to participate in REDD+ or other PES programs. This approach to CBFM would not be relevant and could be antagonistic for communities that do not want to engage in externally-driven conservation programs and development projects on ideological grounds. Indeed, a reliance on drone technology usage could be felt as reinforcing trends toward "modernization" and provoking radical changes in the wants and aspirations of community members. Worryingly, such changes might lead to social conflicts within and among communities.

- Potential social impacts. The use of small drones for monitoring raises a series of social, cultural and political issues. Thus, for instance, drone technology usage might lead to community segmentation by widening the knowledge gap amongst technology users and other community members (younger/older, male/female) and by altering the existing internal power 
dynamics. Engaging in drone-assisted CBFM for REDD+ or other PES projects might cause communities to lose their material and perceived autonomy as regards their socio-economic and cultural traditions (e.g., decrease of time devoted to traditional activities in farming, hunting and foraging as a result of more time spent in forest measurement and monitoring, which may be detrimental for traditional knowledge conservation [110]). Employing small drones for CBFM should thus be subject to social approval and consensus from community members prior to implementation in order to avoid or reduce potential conflicts [111].

- Ethical issues. The most immediate ethical concern is the possibility of privacy violations and the requirements for free, prior and informed consent (FPIC). These issues are pertinent in all instances of the surveillance of people, their properties, resources and activities [35], but are especially salient in the case of small drones because people may feel that a flyover is even further outside their control than are ground surveys. The misuse of drone technology for surveillance without acceptable transparency and communally-agreed rules of engagement could provoke severe conflicts amongst community members (e.g., accusations of privacy violations and spying). Partner organizations could be ultimately blamed for whatever problems that might arise amongst community members as a result of the introduction of drone technology (e.g., conflicts resulting from surveillance of private properties, whether as purposeful espionage or an unintended outcome of forest monitoring). Ethical issues would therefore be a particular concern for organizations introducing small drones to forest communities.

\section{Expected Improvements in Forest Monitoring by Means of Small Drones to Support CBFM Programs}

Given the substantial potential benefits of drone imagery outlined above, we suggest that outstanding improvements in CBFM could be achieved through the utilization of small drones, in addition to limited ground surveys in permanent plots. Aside from the benefits to tropical forest communities, these improvements might be of enormous interest to governments, NGOs and scientists, particularly in the context of REDD+ and other similar PES programs. Specifically, we expect the drone-assisted CBFM approach proposed and evaluated here could deliver improvements in four broad areas:

(1) Improvements in gathering spatially-explicit forest data at the community-wide scale, which is the first stage of data needs for sound CBFM [23]. Drone aerial surveys could be combined with participatory mapping approaches to better identify and map areas of particular interest (e.g., where deforestation, degradation or regrowth processes occur, community boundaries and conflict zones, forest areas under different land tenure arrangements, management types and rules, forest areas sensitive to natural hazards and illegal activities).

(2) Improvements in gathering spatially-explicit forest data at the plot level, which is the second stage of data needs for sound CBFM [23], even though less permanent plots might need to be surveyed and fewer forest variables might need to be measured in them. Plots would be accurately mapped rather than just surveyed on the ground, thus leading to the retrieval of more meaningful forest data.

(3) Achievements in (1) and (2) would lead to improvements in characterizing, at the community scale and for each forest type: (a) forest condition (i.e., level of conservation, degradation 
or recovery); (b) carbon stocks and biodiversity levels; and (c) drivers of deforestation, degradation and regrowth. We posit that the data quality obtained from communities who engage in a well-designed drone-assisted CBFM approach would far exceed what is feasible without community participation using conventional forest monitoring approaches. In the context of REDD+, such data would be much more detailed than the requirements of the highest reporting level of the IPCC (i.e., tier 3). The ability of small drones to map and quantify forest degradation and regrowth, and therefore to improve the estimates of carbon emissions and sequestration related to both processes, would be particularly significant in the context of REDD+ MRV systems. In practice, the second "D" and the "+" of REDD+ are neglected to date, owing to the inability of conventional remote sensing imagery to accurately map degradation and regrowth [112,113], a problem further aggravated in the complex landscape mosaics often found across tropical forests [113].

(4) Improvements in the previous three areas could significantly enhance the modeling of carbon stocks and biodiversity levels at local scales according to different scenarios, as well as validate existing models. More accurate models at local scales would lead to more accurate scaling up to regional/national/international forest modeling efforts such as those commonly undertaken with remote sensing imagery of coarser spatial resolution (e.g., Landsat, MODIS, AVHRR). For instance, at present there is a significant mismatch between above-ground biomass field measurements and estimates from conventional remote sensing data [114]. We believe that a drone-assisted CBFM approach could help bridge this gap and thus improve scaling up above-ground biomass models from which to enhance the estimates of carbon stocks.

Although improvements in these four broad areas would be particularly significant for scientists and other data end-users (e.g., government officials), the improvements in (1) and, to a lesser extent in (2), would be relevant also to those communities that wished to engage in a drone-assisted CBFM approach under REDD+ (or under any project that required community members to monitor their forest resources on a regular basis).

\section{Opportunities and Constraints for Designing and Launching Drone-Assisted Community-Based Forest Monitoring Programs in Tropical Forests}

In this section we discuss further some of the main advantages and disadvantages identified in the previous two sections with the aim of flagging key opportunities and constraints for deploying drone-assisted CBFM programs in tropical countries. We also explain how we envisage a feasible drone-assisted CBFM program in the short-term and give some recommendations about its implementation in tropical contexts, placing emphasis on the needs of REDD+ MRV systems.

On the one hand, the ability to acquire extremely high spatial resolution imagery and at high survey frequencies suggests that the utilization of small drones in CBFM programs would substantially improve what can be "seen" from the air in tropical forests, which would be extremely important for forest data end-users as discussed above. Moreover, having frequent imagery with this level of detail should make it more attractive for communities to engage in CBFM programs because, in addition to potential payments from REDD+ or similar PES programs, communities would be able to better monitor their own territory to spot illegal activities such as logging, mining or land encroachment, as 
well as support any territorial claims they might have. Forest communities might also be empowered by using drone technology if they retained the control of data acquisition and ownership, which could lead to their social and institutional strengthening, thus potentially improving community forest governance and opportunities to negotiate claims regarding their forest resources under REDD+ or similar programs. Drone-assisted CBFM programs should significantly contribute to the decentralization of forest data acquisition and forest management. This would be advantageous for partner organizations and governments in terms of their budget and time constraints insofar as communities retrieved forest data and adhered to the sustainable management strategies deemed necessary to support national and international forest conservation efforts such as REDD $+[18,28,115]$. Furthermore, a well-designed drone-assisted CBFM program should be cost-effective for partner organizations and governments for at least three reasons. First, the costs related to purchasing small drones, training communities to acquire imagery, and performing drone repairs and maintenance would be low compared to acquiring other remote sensing imagery of very high spatial resolution at short time intervals. Second, a drone could be used by several different communities if necessary. And third, the involvement of communities in forest monitoring enables the incorporation of their local knowledge of forests, which should be invaluable as regards the spatio-temporal distribution and direct drivers of forest loss, degradation and regrowth.

On the other hand, several constraints still exist that may cast doubts on the feasibility of launching a successful drone-assisted CBFM program in tropical areas. For example, it is uncertain if country-specific airspace regulations will restrict the use of small drones in communities, although it is unlikely that flying at low altitude within the territorial limits of communities will be prohibited. Also, it is uncertain if the most tropical forest-dependent, traditional societies (i.e., the least acculturated and integrated into the market economy) will be interested in engaging in drone-assisted CBFM in the short-term. Even in communities potentially interested in participating, such as those wanting to engage in REDD+ or similar PES projects, there might be community members opposed to such engagement. We acknowledge that, as happens with the introduction of any technology in rural communities, the introduction of drones can pose a real risk of creating tension and conflicts between community members, and among different communities within the same society. Ethical issues should always be taken into account by researchers, partner organizations, and community leaders. Safety and security issues where illegal activities take place in the forest and violence may be exerted against drone operators and assistance personnel should also be carefully considered.

In addition, for the case of communities whose members are willing to participate in a drone-assisted CBFM program, it is not clear how the communities could approach partner organizations or government agencies to engage in such a program, and what criteria the latter would use to select eligible communities. At this point, we think that attempts to introduce this CBFM approach will have to come from partner organizations and government agencies rather than from communities, though this situation is likely to change in the near future as civil drones' popularity is rapidly increasing [116]. We suggest that small drones could already be used to support ongoing CBFM programs, particularly those related to REDD+ pilot projects, as a way to test their potential to improve monitoring tasks. At the same time, such pilot studies should make their potential negative social impacts visible, as well as the constraints set by the continued need for external assistance and funding for drone repairs and maintenance. To pursue a drone-assisted CBFM, we suggest that forest 
communities would first need to select at least two or three community members who ideally would be computer-literate, have previous experience in managing their forest, and have good communication skills to liaise with partner organizations' personnel and other stakeholders. The participation of women should be encouraged because they usually have specific knowledge of their forests owing to gendered management tasks and therefore women can enrich CBFM programs and should benefit from them [117,118]. Such people would have to receive specific training for as long as necessary [119] so that afterward they would be able to acquire drone imagery of their community forests and visually inspect them to detect areas and types of forest change. Such imagery should then be handed over to partner organizations in a specific format and at specific time intervals, together with the ancillary information previously agreed upon (e.g., a georeferenced image mosaic covering the entire or a specific part of community forests, with information about the direct causes of deforestation, degradation and regrowth). After data delivery, remote sensing analysts and other scientists from partner organizations and/or government agencies would analyze the drone imagery and ancillary data to ensure that the scientific requirements of the funding program (e.g. the MRV system of a REDD+ project) were met. Critically, communities should be timely informed of project results by partner organizations and should retain data rights to use data according to their own convenience and interests. Finally, communities should be allowed to use drones for non-scientific purposes too, most notably for territorial surveillance.

\section{Conclusions}

In this paper we have evaluated the prospects, challenges and opportunities of using small drones for CBFM in tropical areas as a way to improve forest monitoring, which is central to effective REDD+ implementation and other conservation efforts. The subject is very topical and relevant because the reduction and prevention of tropical deforestation and forest degradation is a climate mitigation option with a large and immediate carbon impact globally [31,32], and is essential to global biodiversity conservation [2]. Given the rapid drone technology developments, we argue that the drone-assisted approach to CBFM suggested and evaluated in this paper has a great potential to enhance CBFM. We suggest that this approach is feasible in many tropical locations as long as some degree of community forestry already exists or communities have expressed sincere interest in implementing these new technologies. We expect that most of the current constraints and challenges identified in our assessment will be surmounted relatively soon as technology is rapidly improving in terms of cost, quality and ease of use by non-experts.

In addition, we posit that the utilization of small drones for CBFM in tropical forests has potential benefits for livelihood support despite the potential social problems we have discussed. This CBFM approach could represent an excellent opportunity for communities wishing to enhance their institutional capacities for natural resource governance and thereby the management and conservation of their forest resources, regardless of whether they wish to engage in REDD+ or other similar PES programs as a way to diversify their income sources. The utilization of small drones by communities in CBFM programs should also bring substantial benefits to partner organizations and forest data end-users, who need to respond to current international forest policy data requirements, particularly those of REDD+. Nevertheless, before attempting to implement a drone-assisted forest monitoring program based on 
communities, the potential advantages and disadvantages should be assessed on a case-by-case basis in accordance with the development pathways communities want to pursue, as well as the specific project needs of the partner organizations and end-users.

Overall, the utilization of small drones in CBFM programs has significant potential co-benefits for carbon and biodiversity conservation as a result of improvements in forest monitoring and the capacity to create or enhance national forest inventories in tropical countries, which is key in REDD+ MRV systems. Therefore, organizations engaged in REDD + and government agencies working on REDD+ preparedness should explore and test the most appropriate CBFM approaches that can be integrated into their forest monitoring and safeguard information systems. The drone-assisted CBFM approach put forward and evaluated in this paper could be a good candidate in such efforts because, despite its great potential, empirical research is needed to test it. In our view, the primary issues that need to be carefully examined are the socio-cultural, political and ethical impacts of introducing this monitoring approach in communities, their relevance for community development, and the degree to which communities would need external training, assistance and funding for drone operation.

\section{Acknowledgments}

Jaime Paneque-Gálvez acknowledges financial support from the project "Reinforcing REDD+ Readiness in Mexico and Enabling South-South Cooperation" to carry out this research. The authors are grateful to Margaret Skutsch, who reviewed an earlier version of this paper, as well as to Andrea Laliberte, Adam C. Watts, Luis Miguel Morales and Adrián Peña Cervantes, for providing some insights into the potential of small drones for forest monitoring. The authors are grateful to four anonymous reviewers who greatly helped improve the manuscript with their suggestions.

\section{Author Contributions}

Jaime Paneque-Gálvez and Michael K. McCall designed research. Jaime Paneque-Gálvez performed research. Jaime Paneque-Gálvez wrote two drafts that were reviewed and improved by Michael K. McCall, Brian M. Napoletano, Serge A. Wich and Lian Pin Koh. Jaime Paneque-Gálvez revised the manuscript and the rest of authors read and approved its contents.

\section{Conflict of Interest}

The authors declare no conflict of interest.

\section{References and Notes}

1. Canadell, J.G.; Raupach, M.R. Managing Forests for Climate Change Mitigation. Science 2008, 320, 1456-1457.

2. Bradshaw, C.J.A.; Sodhi, N.S.; Brook, B.W. Tropical Turmoil: A Biodiversity Tragedy in Progress. Front. Ecol. Environ. 2009, 7, 79-87.

3. Maffi, L. Linguistic, Cultural and Biological Diversity. Annu. Rev. Anthropol. 2005, 29, 599-617.

4. Sunderlin, W.D.; Dewi, S.; Puntodewo, A.; Muller, D.; Angelsen, A.; Epprecht, M. Why Forests are Important for Global Poverty Alleviation: A Spatial Explanation. Ecol. Soc. 2008, 13, 24. 
5. Sunderlin, W.D.; Angelsen, A.; Belcher, B.; Burgers, P.; Nasi, R.; Santoso, L.; Wunder, S. Livelihoods, Forests, and Conservation in Developing Countries: An Overview. World Dev. 2005, 33, 1383-1402.

6. Sunderlin, W.D. Poverty Alleviation through Community Forestry in Cambodia, Laos, and Vietnam: An Assessment of the Potential. For. Policy Econ. 2006, 8, 386-396.

7. Porter-Bolland, L.; Ellis, E.A.; Guariguata, M.R.; Ruiz-Mallen, I.; Negrete-Yankelevich, S.; Reyes-Garcia, V. Community Managed Forests and Forest Protected Areas: An Assessment of Their Conservation Effectiveness across the Tropics. For. Ecol. Manag. 2012, 268, 6-17.

8. Referred to forest protected areas, which are forest lands under state management devoted to biological conservation.

9. Bowler, D.E.; Buyung-Ali, L.M.; Healey, J.R.; Jones, J.P.G.; Knight, T.M.; Pullin, A.S. Does Community Forest Management Provide Global Environmental Benefits and Improve Local Welfare? Front. Ecol. Environ. 2011, 10, 29-36.

10. CBFM refers to forest monitoring carried out by community members (usually after receiving training from scientists or partner organizations working with communities), in contrast to more conventional monitoring approaches undertaken by scientists or outside experts. Note that some literature also refers to CBFM as community-based forest management.

11. CBFM may also be required for communities wishing to engage in other payment for ecosystem services (PES) schemes or development projects (e.g., agro-forestry or certified forest products).

12. Danielsen, F.; Skutsch, M.; Burgess, N.D.; Jensen, P.M.; Andrianandrasana, H.; Karky, B.; Lewis, R.; Lovett, J.C.; Massao, J.; Ngaga, Y.; et al. At the Heart of REDD+: A Role for Local People in Monitoring Forests? Conserv. Lett. 2011, 4, 158-167.

13. Skutsch, M.; McCall, M.K. Why Community Forest Monitoring? In Community Forest Monitoring for the Carbon Market: Opportunities under REDD; Skutsch, M., Ed.; Earthscan: Oxford, UK, 2011; pp. 3-15.

14. We use "community forests" to refer to forests inhabited and managed by communities under any forest tenure arrangement (although such forests are often privately or collectively owned).

15. Sandbrook, C.; Nelson, F.; Adams, W.M.; Agrawal, A. Carbon, Forests and the REDD Paradox. Oryx 2010, 44, 330-334.

16. Chhatre, A.; Agrawal, A. Trade-offs and Synergies between Carbon Storage and Livelihood Benefits from Forest Commons. Proc. Natl. Acad. Sci. USA 2009, 106, 17667-17670.

17. Larson, A.M.; Petkova, E. An Introduction to Forest Governance, People and REDD+ in Latin America: Obstacles and Opportunities. Forests 2011, 2, 86-111.

18. Agrawal, A.; Nepstad, D.; Chhatre, A. Reducing Emissions from Deforestation and Forest Degradation. Annu. Rev. Environ. Resour. 2011, 36, 373-396.

19. Scheyvens, H. Community-Based Forest Monitoring for REDD+: Lessons and Reflections from the Field; IGES Policy Brief; Institute for Global Environmental Strategies: Arlington, VA, USA, 2012; p. 10.

20. Larrazábal, A.; McCall, M.K.; Mwampamba, T.H.; Skutsch, M. The Role of Community Carbon Monitoring for REDD+: A Review of Experiences. Curr. Opin. Environ. Sustain. 2012, 4, 707-716. 
21. Pratihast, A.; Herold, M.; Avitabile, V.; de Bruin, S.; Bartholomeus, H.; Souza, C.M., Jr.; Ribbe, L. Mobile Devices for Community-Based REDD+ Monitoring: A Case Study for Central Vietnam. Sensors 2012, 13, 21-38.

22. Knowles, T.; McCall, M.; Skutsch, M.; Theron, L. Preparing Community Forestry for REDD+: Engaging Local Communities in the Mapping and MRV Requirements of REDD+; Pathways for Implementing REDD+: Experiences from Carbon Markets and Communities. Perspectives Series; UNEP Risø Centre: Roskilde, Denmark, 2010.

23. McCall, M.K. Local Participation in Mapping, Measuring and Monitoring for Community Carbon Forestry. In Community Forest Monitoring for the Carbon Market: Opportunities under REDD; Skutsch, M., Ed.; Earthscan: Oxford, UK, 2011; pp. 31-44.

24. Palmer Fry, B. Community Forest Monitoring in REDD+: The "M" in MRV? Environ. Sci. Policy 2011, 14, 181-187.

25. That is, to contribute forest data to typically sparse national inventories based on a relatively small number of permanent plots.

26. Pratihast, A.K.; Herold, M.; de Sy, V.; Murdiyarso, D.; Skutsch, M. Linking Community-Based and National REDD+ Monitoring: A Review of the Potential. Carbon Manag. 2013, 4, 91-104.

27. Joseph, S.; Herold, M.; Sunderlin, W.D.; Verchot, L.V. REDD+ Readiness: Early Insights on Monitoring, Reporting and Verification Systems of Project Developers. Environ. Res. Lett. 2013, 8, doi:10.1088/1748-9326/8/3/034038.

28. Asner, G.P. Satellites and Psychology for Improved Forest Monitoring. Proc. Natl. Acad. Sci. USA 2014, 111, 567-568.

29. Ostrom, E.; Nagendra, H. Insights on Linking Forests, Trees, and People from the Air, on the Ground, and in the Laboratory. Proc. Natl. Acad. Sci. USA 2006, 103, 19224-19231.

30. Skutsch, M. Community Forest Monitoring for the Carbon Market: Opportunities under REDD; Earthscan: Oxford, UK, 2011.

31. Van der Werf, G.; Morton, D.; DeFries, R.; Olivier, J.; Kasibhatla, P.; Jackson, R.; Collatz, G.; Randerson, J. CO ${ }^{2}$ Emissions from Forest Loss. Nat. Geosci. 2009, 2, 737-738.

32. Corbera, E.; Estrada, M.; Brown, K. Reducing Greenhouse Gas Emissions from Deforestation and Forest Degradation in Developing Countries: Revisiting the Assumptions. Clim. Chang. 2010, 100, 355-388.

33. Drones are frequently referred to in the literature as UAV (Unmanned Aerial Vehicles), UAS (Unmanned Aircraft Systems), and less frequently as RPV (Remotely Piloted Vehicles). We avoid using "unmanned" because of its gendered connotation and favor the more generic term "drone", despite the association this term invokes with the US military's controversial air strikes. In cases where this negative connotation may undermine cooperation with communities, we propose the use of alternative terms such as "Remotely Controlled Aircraft Systems" (RCAS) or "Community Aerial Survey Assistant" (CASA).

34. Newcome, L.R. Unmanned Aviation: A Brief History of Unmanned Aerial Vehicles; American Institute of Aeronautics and Astronautics, Inc.: Reston, VA, USA, 2004.

35. Anderson, C. Here Come the Drones; Wired Magazine: London, UK, 2012; pp. 102-111.

36. Esler, D. How UAVs Will Change Aviation. Bus. Commer. Aviat. 2010, 106, 46. 
37. Tomlins, G. Some Considerations in the Design of Low-Cost Remotely-Piloted Aircraft for Civil Remote Sensing Applications. Can. Surv. 1983, 37, 157-167.

38. Tomlins, G.; Manore, M. Remotely Piloted Aircraft for Small Format Aerial Photography. In Proceedings of the Canadian Symposium on Remote Sensing, 8th, and Association Quebecoise de Teledetection, Congress, 4th, Montreal, QC, Canada, 3-6 May 1983; pp. 127-136.

39. Tomlins, G.F.; Lee, Y.J. Remotely Piloted Aircraft-An Inexpensive Option for Large-Scale Aerial Photography in Forestry Applications. Can. J. Remote Sens. 1983, 9, 76-85.

40. Hardin, P.J.; Hardin, T.J. Small-Scale Remotely Piloted Vehicles in Environmental Research. Geogr. Compass 2010, 4, 1297-1311.

41. Nyquist, J.E. Applications of Low-Cost Radio-Controlled Airplanes to Environmental Restoration at Oak Ridge National Laboratory. In Proceedings of the 23rd Annual Association for Unmanned Vehicle Systems International Symposium and Exhibition, Orlando, FL, USA, 15-19 July 1996; Association for Unmanned Vehicle Systems International: Orlando, FL, USA, 1996; pp. 817-829.

42. Quilter, M.C.; Anderson, V.J. Low Altitude/Large Scale Aerial Photographs: A Tool for Range and Resource Managers. Rangel. Arch. 2000, 22, 13-17.

43. Hardin, P.; Jensen, R. Small-Scale Unmanned Aerial Vehicles in Environmental Remote Sensing: Challenges and Opportunities. GISci. Remote Sens. 2011, 48, 99-111.

44. Rango, A.; Laliberte, A.; Steele, C.; Herrick, J.E.; Bestelmeyer, B.; Schmugge, T.; Roanhorse, A.; Jenkins, V. Using Unmanned Aerial Vehicles for Rangelands: Current Applications and Future Potentials. Environ. Pract. 2006, 8, 159-168.

45. Watts, A.C.; Ambrosia, V.G.; Hinkley, E.A. Unmanned Aircraft Systems in Remote Sensing and Scientific Research: Classification and Considerations of Use. Remote Sens. 2012, 4, 1671-1692.

46. Zhang, C.; Kovacs, J. The Application of Small Unmanned Aerial Systems for Precision Agriculture: A Review. Precis. Agric. 2012, 13, 693-712.

47. Hardin, P.J.; Jensen, R.R. Introduction-Small-Scale Unmanned Aerial Systems for Environmental Remote Sensing. GISci. Remote Sens. 2011, 48, 1-3.

48. Boyd, D.; Danson, F. Satellite Remote Sensing of Forest Resources: Three Decades of Research Development. Prog. Phys. Geogr. 2005, 29, 1-26.

49. Foody, G. Remote Sensing of Tropical Forest Environments: Towards the Monitoring of Environmental Resources for Sustainable Development. Int. J. Remote Sens. 2003, 24, 4035-4046.

50. Wulder, M. Optical Remote-Sensing Techniques for the Assessment of Forest Inventory and Biophysical Parameters. Prog. Phys. Geogr. 1998, 22, 449-476.

51. Dubayah, R.O.; Drake, J.B. LiDAR Remote Sensing for Forestry. J. For. 2000, 98, 44-46.

52. Treuhaft, R.N.; Law, B.E.; Asner, G.P. Forest Attributes from Radar Interferometric Structure and Its Fusion with Optical Remote Sensing. BioScience 2004, 54, 561-571.

53. Berni, J.A.J.; Zarco-Tejada, P.J.; Sepulcre-Canto, G.; Fereres, E.; Villalobos, F. Mapping Canopy Conductance and CWSI in Olive Orchards Using High Resolution Thermal Remote Sensing Imagery. Remote Sens. Environ. 2009, 113, 2380-2388. 
54. Hunt, E.; Hively, W.; McCarty, G.; Daughtry, C.; Forrestal, P.; Kratochvil, R.; Carr, J.; Allen, N.; Fox-Rabinovitz, J.; Miller, C. Nir-Green-Blue High-Resolution Digital Images for Assessment of Winter Cover Crop Biomass. GISci. Remote Sens. 2011, 48, 86-98.

55. Booth, D.T.; Cox, S.E. Art to Science: Tools for Greater Objectivity in Resource Monitoring. Rangelands 2011, 33, 27-34.

56. Breckenridge, R.P.; Dakins, M.; Bunting, S.; Harbour, J.L.; White, S. Comparison of Unmanned Aerial Vehicle Platforms for Assessing Vegetation Cover in Sagebrush Steppe Ecosystems. Rangel. Ecol. Manag. 2011, 64, 521-532.

57. Laliberte, A.S.; Goforth, M.A.; Steele, C.M.; Rango, A. Multispectral Remote Sensing from Unmanned Aircraft: Image Processing Workflows and Applications for Rangeland Environments. Remote Sens. 2011, 3, 2529-2551.

58. Laliberte, A.S.; Winters, C.; Rango, A. UAS Remote Sensing Missions for Rangeland Applications. Geocarto Int. 2010, 26, 141-156.

59. Rango, A.; Laliberte, A.; Herrick, J.E.; Winters, C.; Havstad, K.; Steele, C.; Browning, D. Unmanned Aerial Vehicle-Based Remote Sensing for Rangeland Assessment, Monitoring, and Management. J. Appl. Remote Sens. 2009, 3, doi:10.1117/1.3216822.

60. Getzin, S.; Wiegand, K.; Schoening, I. Assessing Biodiversity in Forests Using very High-Resolution Images and Unmanned Aerial Vehicles. Methods Ecol. Evol. 2012, 3, 397-404.

61. Jones, G.P.; Pearlstine, L.G.; Percival, H.F. An Assessment of Small Unmanned Aerial Vehicles for Wildlife Research. Wildl. Soc. Bull. 2006, 34, 750-758.

62. Rodríguez, A.; Negro, J.J.; Mulero, M.; Rodríguez, C.; Hernández-Pliego, J.; Bustamante, J. The Eye in the Sky: Combined Use of Unmanned Aerial Systems and GPS Data Loggers for Ecological Research and Conservation of Small Birds. PLoS One 2012, 7, e50336.

63. Sardà-Palomera, F.; Bota, G.; Viñolo, C.; Pallarés, O.; Sazatornil, V.; Brotons, L.; Gomáriz, S.; Sardà, F. Fine-Scale Bird Monitoring from Light Unmanned Aircraft Systems. IBIS 2012, 154, $177-183$.

64. Watts, A.C.; Perry, J.H.; Smith, S.E.; Burgess, M.A.; Wilkinson, B.E.; Szantoi, Z.; Ifju, P.G.; Percival, H.F. Small Unmanned Aircraft Systems for Low-Altitude Aerial Surveys. J. Wildl. Manag. 2010, 74, 1614-1619.

65. Guichard, F.; Bourget, E.; Agnard, J.-P. High-Resolution Remote Sensing of Intertidal Ecosystems: A Low-Cost Technique to Link Scale-Dependent Patterns and Processes. Limnol. Oceanogr. 2000, 45, 328-338.

66. Hervoue, A.; Dunford, R.; Piegay, H.; Belletti, B.; Tremelo, M.-L. Analysis of Post-Flood Recruitment Patterns in Braided-Channel Rivers at Multiple Scales Based on an Image Series Collected by Unmanned Aerial Vehicles, Ultra-Light Aerial Vehicles, and Satellites. GISci. Remote Sens. 2011, 48, 50-73.

67. Wundram, D.; Löffler, J. High-Resolution Spatial Analysis of Mountain Landscapes Using a Low-Altitude Remote Sensing Approach. Int. J. Remote Sens. 2007, 29, 961-974. 
68. Corbane, C.; Jacob, F.; Raclot, D.; Albergel, J.; Andrieux, P. Multitemporal Analysis of Hydrological Soil Surface Characteristics Using Aerial Photos: A Case Study on a Mediterranean Vineyard. Int. J. Appl. Earth Obs. Geoinform. 2012, 18, 356-367.

69. Ries, J.B.; Marzolff, I. Monitoring of Gully Erosion in the Central Ebro Basin by Large-Scale Aerial Photography Taken from a Remotely Controlled Blimp. Catena 2003, 50, 309-328.

70. Eisenbeiss, H.; Zhang, L. Comparison of DSMs Generated from Mini UAV Imagery and Terrestrial Laser Scanner in a Cultural Heritage Application. In Proceedings of the International Archives of Photogrammetry, Remote Sensing and Spatial Information Sciences XXXVI-5, Dresden, Germany, 25-27 September 2006.

71. Haarbrink, R.; Eisenbeiss, H. Accurate DSM Production from Unmanned Helicopter Systems. Int. Arch. Photogramm. Remote Sens. Spat. Inf. Sci. 2008, 37, 1259-1264.

72. Ambrosia, V.G.; Wegener, S.S.; Sullivan, D.V.; Buechel, S.W.; Dunagan, S.E.; Brass, J.A.; Stoneburner, J.; Schoenung, S.M. Demonstrating UAV-Acquired Real-Time Thermal Data over Fires. Photogramm. Eng. Remote Sens. 2003, 69, 391-402.

73. Casbeer, D.W.; Kingston, D.B.; Beard, R.W.; McLain, T.W. Cooperative Forest Fire Surveillance using a Team of Small Unmanned Air Vehicles. Int. J. Syst. Sci. 2006, 37, 351-360.

74. Merino, L.; Caballero, F.; Ramiro Martinez-de-Dios, J.; Maza, I.; Ollero, A. An Unmanned Aircraft System for Automatic Forest Fire Monitoring and Measurement. J. Intell. Robot. Syst. 2012, 65, 533-548.

75. Hinkley, E.A.; Zajkowski, T. USDA Forest Service-NASA: Unmanned Aerial Systems Demonstrations-Pushing the Leading Edge in Fire Mapping. Geocarto Int. 2011, 26, 103-111.

76. Aber, J.S.; Aber, S.W.; Pavri, F. Unammned Small Format Aerial Photography from Kites Acquiring Large-Scale, High-Resolution, Multiview-Angle Imagery. In Proceedings of the Pecora 15/Land Satellite Information IV/ISPRS Commission I/FIEOS 2002, Denver, CO, USA, 8-15 November 2002; ASPRS: The Imaging \& Geospatial Information Society: Denver, CO, USA, 2002; pp. 1-6.

77. Aber, J.S.; Sobieski, R.J.; Distler, D.A.; Nowak, M.C. Kite Aerial Photography for Environmental Site Investigations in Kansas. Trans. Kansas Acad. Sci. 1999, 102, 57-67.

78. Dunford, R.; Michel, K.; Gagnage, M.; Piegay, H.; Tremelo, M.L. Potential and Constraints of Unmanned Aerial Vehicle Technology for the Characterization of Mediterranean Riparian Forest. Int. J. Remote Sens. 2009, 30, 4915-4935.

79. Hung, C.; Bryson, M.; Sukkarieh, S. Multi-Class Predictive Template for Tree Crown Detection. ISPRS J. Photogramm. Remote Sens. 2012, 68, 170-183.

80. Lin, Y.; Hyyppa, J.; Jaakkola, A. Mini-UAV-Borne LiDAR for Fine-Scale Mapping. IEEE Geosci. Remote Sens. 2011, 8, 426-430.

81. Mäkynen, J.; Saari, H.; Holmlund, C.; Mannila, R.; Antila, T. Multi- and Hyperspectral UAV Imaging System for Forest and Agriculture Applications. In Next-Generation Spectroscopic Technologies V; Druy, M.A., Crocombe, R.A., Eds.; Proc. SPIE: Baltimore, Maryland, USA, 2012; 8374, pp. 1-9. 
82. Saari, H.; Pellikka, I.; Pesonen, L.; Tuominen, S.; Heikkilä, J.; Holmlund, C.; Mäkynen, J.; Ojala, K.; Antila, T. Unmanned Aerial Vehicle (UAV) Operated Spectral Camera System for Forest and Agriculture Applications. In Proceedings of the SPIE, Remote Sensing for Agriculture, Ecosystems, and Hydrology XIII, Prague, Czech Republic, 19 September 2011; p. 81740H.

83. Lisein, J.; Pierrot-Deseilligny, M.; Bonnet, S.; Lejeune, P. A Photogrammetric Workflow for the Creation of a Forest Canopy Height Model from Small Unmanned Aerial System Imagery. Forests 2013, 4, 922-944.

84. Wallace, L.; Lucieer, A.; Watson, C.; Turner, D. Development of a UAV-LiDAR System with Application to Forest Inventory. Remote Sens. 2012, 4, 1519-1543.

85. Horcher, A.; Visser, R.J. Unmanned Aerial Vehicles: Applications for Natural Resource Management and Monitoring. In Proceedings of the Council on Forest Engineering Proceedings 2004: Machines and People, The Interface, Hot Springs, AR, USA, 27-30 April 2004.

86. Koh, L.P.; Wich, S.A. Dawn of Drone Ecology: Low-Cost Autonomous Aerial Vehicles for Conservation. Trop. Conserv. Sci. 2012, 5, 121-132.

87. A good source of drone/UAV news is the GIM periodical (http://www.gim-international.com/). Other sources include commercial websites that offer mapping services using drones (which we do not identify to avoid favoring any particular company) and websites of university research teams concerned with the development and use of drones for environmental issues. YouTube is also an excellent source of information.

88. Further information can be found in the Internet on websites such as http://conservationdrones.org/, http://rhino-uav.org/, http://www.iapf.org/en/campaigns/iapfdrone, http://wwf.panda.org/?206154/ nepal-tests-new-unmanned-aerial-vehicle-technology-to-stop-wildlife-crime.

89. Payload refers to the carrying capacity of the aircraft, measured in terms of weight, and includes the equipment it carries (batteries, cameras, data logger, etc.).

90. Everaerts, J. The Use of Unmanned Aerial Vehicles (UAVs) for Remote Sensing and Mapping. In Proceedings of the XXI ISPRS Congress, Beijing, China, 3-11 July 2008; ISPRSInternational Society for Photogrammetry and Remote Sensing: Beijing, China, 2008; pp. $1187-1191$.

91. It is important to note that while most environmental applications presently use small drones, there is a trade-off between the size of the drone and the accuracy of the data that it can collect.

92. However, we are aware of instances where such drones have covered up to 50 ha, so they may serve in small forest communities.

93. Vertical landing is also advantageous because the lower speed inherent to this type of landing reduces the likelihood of the equipment suffering impact damages.

94. Note, however, that many of the publications cited in this paper have not used small, fixed-wing aircraft.

95. Most probably the partner organizations and forest data end-users would be government agencies, environmental or development NGOs, and research teams. Note that partner organizations would not necessarily be data end-users and also that community members might also, in certain instances, become data end-users. 
96. We believe that the approach which we envisage for the entire process of implementing CBFM assisted by small drones is the most feasible and desirable in the short-term, particularly given current constraints. However, we expect that as technology becomes easier to use and forest monitoring decentralization advances, forest communities could undertake all the necessary processing tasks without the assistance of partner organizations. This premise might also be valid for drone repairs and maintenance in certain cases, but this technological diffusion will be likely be slower and more problematic.

97. Importantly, partner organizations and governments could use this spatial information to produce highly accurate maps of forest cover change. Moreover, coupled with community local knowledge of the main drivers of such forest change, the quality of data obtained from communities would far exceed what is feasible to achieve without their participation, and would be much more detailed than the requirements of the highest reporting level of the IPCC (i.e. tier 3).

98. Lynch, J.; Maslin, M.; Balzter, H.; Sweeting, M. Choose Satellites to Monitor Deforestation. Nature 2013, 496, 293-294.

99. Quesada, M.; Sanchez-Azofeifa, G.A.; Alvarez-Añorve, M.; Stoner, K.E.; Avila-Cabadilla, L.; Calvo-Alvarado, J.; Castillo, A.; Espírito-Santo, M.M.; Fagundes, M.; Fernandes, G.W.; et al. Succession and Management of Tropical Dry Forests in the Americas: Review and New Perspectives. For. Ecol. Manag. 2009, 258, 1014-1024.

100. Birdsey, R.; Angeles-Perez, G.; Kurz, W.A.; Lister, A.; Olguin, M.; Pan, Y.; Wayson, C.; Wilson, B.; Johnson, K. Approaches to Monitoring Changes in Carbon Stocks for REDD+. Carbon Manag. 2013, 4, 519-537.

101. Note that these images would be georeferenced but not orthorectified, which would entail further, more technical processing, that might be needed by certain end-users but not the communities.

102. ConservationDrones. Available online: http://conservationdrones.org (accessed on 12 October 2013).

103. Engineering.com. Available online: http://www.engineering.com/3DPrinting/3DPrintingArticles/ ArticleID/5965/3D-Printed-Surveillance-Drone-Takes-Flight.aspx (accessed on 12 October 2013).

104. 3D printer and 3D printer news. Available online: http://www.3ders.org/articles/20130607french-drone-maker-uses-3d-printers-to-prototype-uav-parts.html (accessed on 12 October 2013).

105. NewScientist. Available online: http://www.newscientist.com/article/dn20737-3d-printing-theworlds-first-printed-plane.html (accessed on 12 October 2013).

106. Reyes-García, V.; Ledezma, J.C.; Paneque-Gálvez, J.; Orta, M.; Gueze, M.; Lobo, A.; Guinart, D.; Luz, A.C. Presence and Purpose of Nonindigenous Peoples on Indigenous Lands: A Descriptive Account from the Bolivian Lowlands. Soc. Nat. Resour. 2012, 25, 270-284.

107. As long as they complied with a previously established minimum number of annual surveys.

108. Note that at equal camera sensor size and focal length, the lower the flight altitude, the higher the spatial resolution of the imagery acquired (i.e. the smaller the pixel size). Currently, small drones can acquire imagery at a spatial resolution of even 1-2 cm per pixel side (e.g., $2.2 \mathrm{~cm}$ flying at $100 \mathrm{~m}$ above the ground using a camera with a sensor size of $6.17 \times 4.55 \mathrm{~mm}$ and a focal length of $6.9 \mathrm{~cm}$; see for instance [80]).

109. Rango, A.; Laliberte, A.S. Impact of Flight Regulations on Effective Use of Unmanned Aircraft Systems for Natural Resources Applications. J. Appl. Remote Sens. 2010, 4, doi:10.1117/ 1.3474649 . 
110. Reyes-García, V.; Guèze, M.; Luz, A.C.; Paneque-Gálvez, J.; Macía, M.J.; Orta-Martínez, M.; Pino, J.; Rubio-Campillo, X. Evidence of Traditional Knowledge Loss Among a Contemporary Indigenous Society. Evol. Hum. Behav. 2013, 34, 249-257.

111. Nevertheless, there would be little difference in this regard between a drone-assisted CBFM approach and one based solely on community ground surveys, as either approach would entail the introduction of technology and foreign practices and a subsequent cultural change (even if minor).

112. Pearson, T.R.H.; Brown, S.; Casarim, F.M. Carbon Emissions from Tropical Forest Degradation Caused by Logging. Environ. Res. Lett. 2014, 9, doi:10.1088/1748-9326/9/3/034017.

113. Mertz, O.; Müller, D.; Sikor, T.; Hett, C.; Heinimann, A.; Castella, J.-C.; Lestrelin, G.; Ryan, C.M.; Reay, D.S.; Schmidt-Vogt, D.; et al. The Forgotten D: Challenges of Addressing Forest Degradation in Complex Mosaic Landscapes under REDD+. Geogr. Tidsskr.-Dan. J. Geogr. 2012, 112, 63-76.

114. Mitchard, E.T.A.; Feldpausch, T.R.; Brienen, R.J.W.; Lopez-Gonzalez, G.; Monteagudo, A.; Baker, T.R.; Lewis, S.L.; Lloyd, J.; Quesada, C.A.; Gloor, M.; et al. Markedly Divergent Estimates of Amazon Forest Carbon Density from Ground Plots and Satellites. Glob. Ecol. Biogeogr. 2014, doi:10.1111/geb.12168.

115. Phelps, J.; Webb, E.L.; Agrawal, A. Does REDD+ Threaten to Recentralize Forest Governance? Science 2010, 328, 312-313.

116. We already know of cases in Latin America where indigenous peoples are interested in finding out about the feasibility of using drones in their territories. In these cases, we posit that as long as communities are politically organized and have leaders who already collaborate with academia, NGOs or government agencies, the negotiation for the implementation of a drone-assisted CBFM might be feasible.

117. Setyowati, A. Ensuring That Women Benefit from REDD+. Unasylva (FAO) 2012, 63, 57-62.

118. Peach Brown, H.C. Gender, Climate Change and REDD+ in the Congo Basin Forests of Central Africa. Int. For. Rev. 2011, 13, 163-176.

119. We do not think more than two weeks would be needed, even for community members failing to meet the two main criteria for selection (computer-literacy and experience in forest management), particularly if drones are to be used with an autopilot system (i.e., in automatic or semi-automatic flight mode). This issue, however, requires further investigation.

(C) 2014 by the authors; licensee MDPI, Basel, Switzerland. This article is an open access article distributed under the terms and conditions of the Creative Commons Attribution license (http://creativecommons.org/licenses/by/3.0/). 